\title{
SISTEMA PARA GERENCIAMENTO E MANEJO DE ÁRVORES EM AMBIENTE URBANOS COM FOCO EM CIDADES INTELIGENTES
}

\author{
Gabriel Dias Marinho, Joaquim Pessoa Filho e Leandro Pupo Natale \\ Universidade Presbiteriana Mackenzie \\ Rua da Consolação, 930 - São Paulo, S.P., Brasil
}

\begin{abstract}
RESUMO
Muitos problemas têm surgido nas cidades devido ao avanço populacional nas áreas metropolitanas, concorrendo com áreas verdes principalmente. Desta forma, a queda de árvores torna-se um problema frequente devido principalmente a fatores, como tempo excessivo entre podas, chuvas intensas com reduzidos espaços para absorção desta água, e apodrecimento de raízes devido a ausência de manejo adequado, dentre outros. Este tipo de situação poderia ser evitada, otimizando ainda a preservação das áreas verdes através do uso de tecnologias de monitoramento e gestão. Este projeto propõe uma arquitetura sistêmica para o gerenciamento do manejo de árvores em áreas urbanas, utilizando tecnologias de sensoriamento e conceitos de cidades inteligentes, a fim de preservar e prevenir quedas incidentes que venham a interferir ainda mais em vias públicas ou equipamentos públicos.
\end{abstract}

\section{PALAVRAS-CHAVE}

Cidades Inteligentes, Internet das Coisas, Ontologia

\section{INTRODUÇÃO}

Segundo relatório da ONU[UNRIC] estima-se que a população mundial deva crescer mais de 2 milhões de pessoas até 2050, além disso, estima-se que pelo menos dois terços da população mundial habitará em cidades, aumentando os desafios para os responsáveis pelo gerenciamento das cidades. Para que seja possível acomodar uma grande quantidade de pessoas nas áreas urbanas, tecnologias de informação e comunicação podem ser empregadas para coletar e analisar uma grande quantidade de informações geradas por diversas fontes de dados da cidade[KON], como, redes de sensores, sistemas de trânsito e dispositivos dos cidadãos. Esses dados podem ser utilizados de formas inovadoras para criação de aplicações integradas que melhorem os serviços da cidade e o uso de seus recursos.

O gerenciamento das áreas verdes nas regiões urbanas também é um grande desafio administrativo. Neste sentido, questões relacionadas à queda de árvores causadas por chuvas intensas, ventos e potencializado pela falta do manejo adequado desta vegetação arbórea criam graves problemas relacionados a riscos de acidentes, danos materiais, interrupção de vias públicas, do fornecimento de energia elétrica ou de serviços de telecomunicações.

Este projeto propõe o uso de um sistema capaz de fornecer a gestores urbanos, municípios e outras entidades relacionadas, informações importantes como priorização de períodos específicos de poda para cada espécie, controle de pragas, identificação de áreas de risco, identificação das principais espécies e sua distribuição nas áreas urbanas, entre outras possibilidades.

O objetivo da pesquisa deste projeto é analisar os conceitos relacionados a cidades inteligentes, pesquisar os aspectos necessários aos serviços de manejo de árvores em áreas urbanas, propondo uma solução tecnológica para identificação única das árvores de forma a informatizar o manejo destes ativos verdes urbanos. 


\section{DESENVOLVIMENTO}

A arquitetura proposta neste projeto, representada na figura 1, tem por objetivo armazenar e fornecer um calendário anual e dinâmico de manejo das árvores a administradores públicos, baseado também em normas específicas, estabelecidas por cada municipalidade [ABNT-NBR, 2013], possibilitando interação através de ambiente web.

A implementação de um sistema baseado nesta arquitetura, permitirá fornecer dados específicos para que os administradores públicos possam tomar ações preventivas evitando desastres ambientais e municipais Este prevê três tipos de usuários (administrador, podador e usuário comum), com visões distintas sobre o sistema. O sistema disponibiliza um módulo público para a divulgação dos dados das árvores a todos os cidadãos de forma online, possibilitando um engajamento social, além disso este módulo também permite aos cidadãos informarem questões relacionadas às árvores de forma a agilizar a entrada de informações no sistema, tais como, a funcionalidade de cadastro de solicitação de poda, que poderá ser realizada por qualquer usuário do sistema.

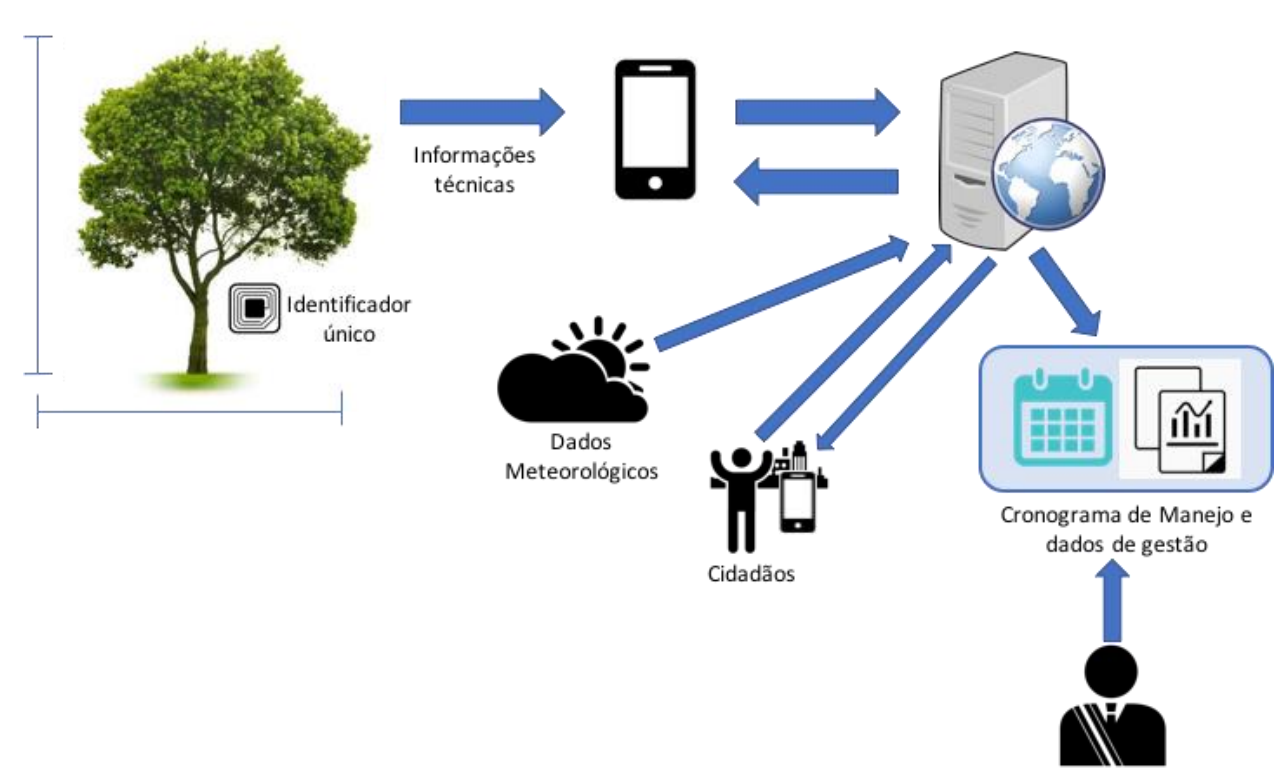

Figura 1. Arquitetura proposta para o projeto

\section{CONCLUSÃO}

Este projeto tem como objetivo melhorar o manejo de árvores através do uso de tecnologias e conceitos de cidades inteligentes, utilizando dispositivos IoT para identificar unicamente os ativos verdes de uma cidade, criando assim um identificador único [CAMPOS, 2016]. Também será definida uma base de dados ontológica contendo informações (como por exemplo: nome, espécie, localização, última data de poda e entre outros a serem definidos em fase de projeto) de forma a criar uma base de conhecimento[NATALE].

A partir desta base de conhecimento será criada uma plataforma computacional responsável por gerenciar automaticamente os ativos verdes, e assim propor o manejo específico para cada árvore em um cronograma eficiente. Para esta tarefa a aplicação utilizará além dos dados de cadastro das árvores, histórico do clima urbano, previsão do tempo, informações reportadas pelos cidadãos, e outras informações identificadas durante o tempo de projeto. 


\section{REFERÊNCIAS}

ABNT-NBR 16246-1, 2013. Florestas urbanas - Manejo de árvores, arbustos e outras plantas lenhosas.

Campos, Leonardo Barreto, 2016. Towards an IoT-based system for Smart City. 2016 IEEE International Symposium on Consumer Electronics (ISCE), p. 129-130.

Kon, Fabio; Santana, Eduardo Felipe Zambom, 2017. Computação aplicada a Cidades Inteligentes: Como dados, serviços e aplicações podem melhorar a qualidade de vida nas cidades. Anais, cap. 4.

Natale, Leandro Pupo; OMAR, Nizam, 2013. Utilização de Bancos de Dados Ontológicos em Integração de Bases de Dados Heterogêneas. In: Proceedings of International Conference on Engineering and Computer Education, p. 292-296.

UNRIC, 2013 - Relatório das Nações Unidas estima que a população mundial alcance os 9,6 mil milhões em 2050. https://www.unric.org/pt/actualidade/31160-relatorio-das-nacoes-unidas-estimaque-a-populacao-mundial-alcance-os96mil-milhoes-em-2050- 